\title{
A Survey of the Tutorial System for Young Teachers at Independent Colleges in China: A Case Study of Jiangsu University Jingjiang College
}

\author{
Peng Xue*, Hao Ma \\ Department of Human Resources, Jiangsu University Jingjiang College, Zhenjiang, China
}

Email address:

sxllxp@ujs.edu.cn (Peng Xue)

${ }^{*}$ Corresponding author

To cite this article:

Peng Xue, Hao Ma. A Survey of the Tutorial System for Young Teachers at Independent Colleges in China: A Case Study of Jiangsu University Jingjiang College. Science Journal of Education. Vol. 8, No. 2, 2020, pp. 41-46. doi: 10.11648/j.sjedu.20200802.12

Received: March 29, 2020; Accepted: April 17, 2020; Published: April 28, 2020

\begin{abstract}
The quality of higher education is decided by the quality of college teachers, among whom young teachers undertake a vital role for its sustainable development. Taken this into consideration, this paper aims to reveal the current situations of the tutorial system for young teachers at independent colleges in China through SPSS analyses to verify the necessity and efficacy of applying such a tutorial system, resolve the problem of "insufficient experience in teaching though having a fair understanding of theories" among young teachers, and promote the healthy development of young teachers at tertiary-level education. Results indicate that the tutorial system encounters three difficulties: (1) the young teachers do not recognize the value of and lack of initiatives for participating the tutorial system, (2) their tutors do not function effectively mainly due to the short of collaborations among tutors, and (3) the system itself lacks of professional evaluations. As counter-measures, the paper proposes that the college administration should (1) foster a culture for teacher professional development and expand the influence of the tutorial system for young teachers, (2) provide concrete supportive measures and monitor the whole process of implementing the tutorial system; (3) perfect the evaluation of the tutorial system and highlight formative evaluations from the tutors; (4) offer more thorough plans to direct the development of the tutorial system; and (5) perfect the make-up of the tutors and utilize modern information technologies for the tutorial system.
\end{abstract}

Keywords: Independent Colleges, Young Teachers, The Tutorial System for Young Teachers (TSYT)

\section{Introduction}

With the rapid expansion of China's higher education, the popularization of higher education is coming. Under this background, colleges employ more and more young teachers. Though this brings more teaching faculties to higher educational institutions, it also leads to several teaching-quality related problems [1][2]. As is widely known, the quality of higher education is determined by the quality of the teachers serve in it, and its sustainable development depends more on young teachers, especially during the transitional stage from elite to mass education. Young teachers themselves are also eager to fulfil the role-change from students to teachers quickly so that they could satisfy the high-demanding teaching and research requirements of colleges [3]. Therefore, colleges abroad and at home emphasize the importance of establishing and promoting the tutorial system for young teachers (TSYT for short hereafter) to solve young teachers' problem of lacking practical experiences though with fair theoretical knowledge and promote their professional development.

\section{Background for Implementing the Tutorial System for Young Teachers}

\subsection{Theoretical Background}

The Tutorial System for Young Teachers (TSYT) refers to a teaching management system in which a college selects and designates teachers of rich teaching and research experiences and at the same time of high virtues to be tutors of the young teachers in the college in order to promote the latter's 
professional development. The TSYT is designed to solicit the tutors' instruction, help and guidance, and to speed up young teachers' professional development in their teaching and research. It is a fundamental initiative for faculty development for colleges and a key means for in-service professional training [4].

The TSYT originates from Collins \& Brown's Cognitive Apprenticeship [5]. The theory of Cognitive Apprenticeship advocates to put apprentice teachers into real professional contexts to improve their critical thinking ability, problem-solving skills and the capacities of dealing with complicated matters by solving the invisibility of professional skills in traditional apprenticeship and the separation of knowledge transmission from its application in traditional school education [6]. The TSYT is such a young teacher training system in which apprentice teachers (young teachers) are put into the teaching and research practice of professionals (tutors) with the aim to enhance their critical thinking ability, problem-solving skills and capacities of dealing with complicated matters [7].

The TSYT has a long history in China. For example, it appears as such familiar terms "Tutor-Apprentice Pair", "Green-Blue Project", etc. in official documents like Interim Provisions on the Selection of Special-Grade Teachers (1978), Suggestions on Training Probation Teachers at Primary Schools (1994). The TSYT still enjoys great popularity at colleges, and it does bring about many excellent teachers, so the system plays an indispensable role in school-based teacher training.

\subsection{Practical Background}

Jiangsu University Jingjiang College is a teaching-oriented college of educating applicative talents, and teaching is not only its primary concern but also serves as the key to update the college's education quality. In accordance with the requirements of China's Ministry of Education, Jingjiang College has to separate from its afflicted entity (i.e., Jiangsu University), and establish an independent professional and highly skilled teaching faculty to fulfill this separation after the college moves to a new location. Therefore, the college has recruited in recent years many young teachers who have profound theoretical knowledge and are energetic in teaching.

In order to promote the professional development of these young teachers, Jingjiang College has implemented the TSYT and formulated Regulations on Assistant Teaching for Young Teachers, Jingjiang College to provide policy and system guarantee for young teachers' quick transformation from students to teachers. The regulations have resolved the limitations and difficulties of implementing the tutorial system, speeded up young teachers' mastery of teaching skills, raised their teaching levels, promoted their professional development and thus enhanced the overall teaching quality of the college. It has stimulated the development of students, young teachers and the independent college, and therefore could be considered a good beginning and hallmark of establishing a full-time faculty in independent colleges.

\section{SPSS Analyses of the Achievements and Limitations of the TSYT}

\subsection{Source of the Sampling Data and Explanation on Data Analysis}

The samples of the study are young teachers recruited in 2015 by Jiangsu University Jingjiang College. Those without tutors are labeled as Group A, and are coded as A1 - A5 respectively in Table 1 . Those with tutors are labeled as Group $\mathrm{B}$, and are coded as B1 - B16 respectively. The four scores after the name codes stand for the young teachers' ratings when they were recruited in the year 2015 and the next subsequent 3 years (i.e., 2016, 2017, 2018). The data were processed in SPSS 19.0 for further analyses.

Table 1. Ratings of Non-tutored Young Teachers at, Jiangsu University Jingjiang College.

\begin{tabular}{llllll}
\hline Name & $\mathbf{2 0 1 5}$ & $\mathbf{2 0 1 6}$ & $\mathbf{2 0 1 7}$ & $\mathbf{2 0 1 8}$ & Mean \\
\hline A1 & 91.83 & 91.6 & 92.39 & 91.99 & 91.99 \\
A2 & 89.67 & 91.6 & 92.09 & 92.67 & 92.12 \\
A3 & 91.67 & 92 & 92.46 & 92.18 & 92.21 \\
A4 & 90.6 & 91 & 92.12 & 92.35 & 91.82 \\
A5 & 85.33 & 86.8 & 92.33 & 91.84 & 90.32 \\
\hline
\end{tabular}

Table 2. Ratings of Tutored Young Teachers at Jiangsu University Jingjiang College.

\begin{tabular}{llllll}
\hline Name & $\mathbf{2 0 1 5}$ & $\mathbf{2 0 1 6}$ & $\mathbf{2 0 1 7}$ & $\mathbf{2 0 1 8}$ & Mean \\
\hline B1 & 83.8 & N/A & 87.6 & 91.71 & 89.66 \\
B2 & 83.2 & 91.6 & 88.8 & 90.29 & 90.23 \\
B3 & 85.6 & N/A & N/A & 91.4 & 91.40 \\
B4 & 78 & 91.2 & 87.4 & 91.95 & 90.18 \\
B5 & 90 & N/A & 84.4 & 92.59 & 88.50 \\
B6 & 89 & 89.4 & 85.8 & 91.68 & 88.96 \\
B7 & 84.8 & 87 & 81.8 & 90.07 & 86.29 \\
B8 & 80.8 & 88 & 84 & 92.42 & 88.14 \\
B9 & 88 & 91.6 & 92.2 & 92.53 & 92.11 \\
B10 & 85 & N/A & N/A & 92.17 & 92.17 \\
B11 & 83 & 86.4 & 88.6 & 92.08 & 89.03 \\
B12 & 84.4 & N/A & 88.6 & 90.32 & 89.46 \\
B13 & 82.4 & 86.4 & 87 & 92.24 & 88.55 \\
B14 & 86.8 & 87.6 & 82.4 & 91.11 & 87.04 \\
B15 & 84.8 & 91.8 & 88.2 & 92.57 & 90.86 \\
B16 & 84.5 & N/A & 82.6 & 92.06 & 87.33 \\
\hline
\end{tabular}

Note: some of the young teachers did not submit their ratings in certain years, and thus N/A is used to indicate the absence of data.

\subsection{Achievements of the TSYT}

The study yields the following research findings and several conclusions with related statistical analyses in SPSS 19.0 .

(1) A Comparison between Pre-service and In-service Ratings of Non-tutored Teachers

The study first calculated the mean score after the non-tutored teachers have been recruited, that is, their ratings in 2016-2018, and compared this mean score after recruitment (i.e., in-service) with their ratings when being recruited in 2015 (i.e., pre-service). The rationale for this comparison is to find out whether the non-tutored teachers' ratings differ significantly when and after their recruitment. 
With the paired-sampled $t$-test, it is found the $t=-2.148$, and Sig. $=0.098>.05$, as shown in Table 3. This indicates the non-tutored young teachers' ratings are not significantly different when they were recruited and in the next three subsequent years.

Table 3. Comparison between Pre-service and In-service Ratings of Non-tutored Teachers.

\begin{tabular}{|c|c|c|c|c|c|c|c|c|}
\hline & \multicolumn{5}{|c|}{ Symmetric difference } & \multirow{3}{*}{$t$} & \multirow{3}{*}{ df } & \multirow{3}{*}{$\begin{array}{l}\text { Sig. } \\
\text { (two-tailed) }\end{array}$} \\
\hline & \multirow{2}{*}{ MEAN } & \multirow{2}{*}{ SD } & \multirow{2}{*}{$\begin{array}{l}\text { standard error } \\
\text { of mean }\end{array}$} & \multicolumn{2}{|c|}{ 95\% confidence interval for difference } & & & \\
\hline & & & & lower-bound & upper-bound & & & \\
\hline Pre-service vs. In-service & -1.87200 & 1.94848 & .87139 & -4.29136 & .54736 & -2.148 & 4 & .098 \\
\hline
\end{tabular}

(2) A Comparison between Pre-service and In-service Ratings of Tutored Teachers

The study also conducts a comparison between the tutored teachers' pre-service and in-service ratings. Paired samples $t$-test indicates that there is a mean score increase of 4.7381 and the young teachers' in-service ratings are significantly higher than those of pre-service $(\mathrm{t}=-5.505, \mathrm{df}=3$, Sig. $=.000)$ (Table 4).

Table 4. Comparison between Pre-service and In-service Ratings of Tutored Teachers.

\begin{tabular}{|c|c|c|c|c|c|c|c|c|}
\hline & \multicolumn{5}{|c|}{ Symmetric difference } & \multirow{3}{*}{$t$} & \multirow{3}{*}{ df } & \multirow{3}{*}{$\begin{array}{l}\text { Sig. } \\
\text { (two-tailed) }\end{array}$} \\
\hline & \multirow{2}{*}{ MEAN } & \multirow{2}{*}{ SD } & \multirow{2}{*}{$\begin{array}{l}\text { standard error } \\
\text { of mean }\end{array}$} & \multicolumn{2}{|c|}{ 95\% confidence interval for difference } & & & \\
\hline & & & & lower-bound & upper-bound & & & \\
\hline Pre-service vs. In-service & -4.73812 & 3.44268 & .86067 & -6.572260 & -2.90365 & -5.505 & 15 & .000 \\
\hline
\end{tabular}

(3) A Comparison of Pre-Service Ratings between Non-tutored and Tutored Teachers

Table 5 reports the paired-samples $t$-test for non-tutored and tutored teachers' ratings when they were recruited (i.e., pre-service). The results indicate equal variances could be assumed with $\mathrm{F}=0.065$, Sig. $=0.802$. From the $t$-test for
Equality of Means, it can be observed that non-tutored teachers' ratings are significantly higher than those of tutored ones $(t=2.499$, Sig. $=.022<.05)$. This also indicates the necessity of the TSYT for young teachers, especially those of lower ratings.

Table 5. Comparison of Pre-service Ratings between Non-tutored and Tutored Teachers.

\begin{tabular}{|c|c|c|c|c|c|c|c|c|}
\hline & \multicolumn{3}{|c|}{$\begin{array}{l}\text { Levene's Test for } \\
\text { Equality of Variances }\end{array}$} & \multicolumn{5}{|c|}{$t$-test for Equality of Means } \\
\hline & \multirow{2}{*}{$\mathbf{F}$} & \multirow{2}{*}{ Sig. } & \multirow{2}{*}{$\mathbf{t}$} & \multirow{2}{*}{$\begin{array}{l}\text { Sig. } \\
\text { (2-tailed) }\end{array}$} & \multirow{2}{*}{$\begin{array}{l}\text { Mean } \\
\text { difference }\end{array}$} & \multirow{2}{*}{$\begin{array}{l}\text { standard error } \\
\text { of mean }\end{array}$} & \multicolumn{2}{|c|}{$95 \%$ confidence interval for difference } \\
\hline & & & & & & & lower-bound & upper-bound \\
\hline Equal variances assumed & 065 & $80 ?$ & 2.499 & .022 & 3.78875 & 1.51638 & .61493 & 6.96257 \\
\hline Equal variances not assumed & .065 & .802 & 2.571 & .037 & 3.78875 & 1.47346 & .30764 & 7.26986 \\
\hline
\end{tabular}

(4) A Comparison of the Three In-service Ratings between Non-tutored and Tutored Teachers

Table 6 reports the independent $t$-test results of the three ratings of tutored and non-tutored young teachers after recruitment in the years of 2016-2018. It can be seen that the $\mathrm{F}$ value in the Levene's Test is 3.307, Sig. $=.085>.05$, which equal variances could be assumed. In the $t$-test for Equality of Means, the $t$ value is 2.862 , Sig. (2-tailed) value is $.010<.05$, and this indicates there exists a significant difference between tutored and non-tutored teachers' ratings. Combined with the data in Table 5, it can be drawn that the tutored teachers' ratings raised drastically after their recruitment.

Table 6. Comparison of In-service Ratings between Non-tutored and Tutored Teachers.

\begin{tabular}{|c|c|c|c|c|c|c|c|c|}
\hline & \multicolumn{3}{|c|}{$\begin{array}{l}\text { Levene's Test for } \\
\text { Equality of Variances }\end{array}$} & \multicolumn{5}{|c|}{$t$-test for Equality of Means } \\
\hline & \multirow{2}{*}{$\mathbf{F}$} & \multirow{2}{*}{ Sig. } & \multirow{2}{*}{$\mathbf{t}$} & \multirow{2}{*}{$\begin{array}{l}\text { Sig. } \\
\text { (2-tailed) }\end{array}$} & \multirow{2}{*}{$\begin{array}{l}\text { Mean } \\
\text { difference }\end{array}$} & \multirow{2}{*}{$\begin{array}{l}\text { standard error } \\
\text { of mean }\end{array}$} & \multicolumn{2}{|c|}{ 95\% confidence interval for difference } \\
\hline & & & & & & & lower-bound & upper-bound \\
\hline \multirow{2}{*}{$\begin{array}{l}\text { Equal variances assumed } \\
\text { Equal variances not assumed }\end{array}$} & \multirow{2}{*}{3.307} & \multirow{2}{*}{.085} & 2.862 & .010 & 2.32863 & .81356 & .62593 & 4.03142 \\
\hline & & & 4.176 & .001 & 2.32863 & .55759 & 1.14600 & 3.51125 \\
\hline
\end{tabular}

Based on Tables 2-5, the following conclusions can be drawn: the TSYT plays a vital role in promoting the teaching and research capacities of newly recruited young college teachers, and tutored teachers develop much better than those without tutors. Therefore, the TSYT is found very helpful for the professional development of college young teachers.

\subsection{Limitations of TSYT}

Still, some problems have also been detected when the
TSYT is under implementation, and these can be summarized at the cognitive, implementational, and evaluative levels.

(1) Neglect of Its Importance, and Inactiveness of Participation

Some of the tutors and young teachers have not fully realized the value of the TSYT, which leads to their inactive participation in this system. From the perspective of tutors, there are no enough rewards to ensure their high participation, though they could get some allowance from the college. From the perspective of college administrations, the assessment for 
this TSYT is not enough scientific, and the tutors getting a fix amount of allowance no matter how good or bad they did in the TSYT. This has a negative impact on the implementation of the TSYT. From the perspective of young teachers, they are given a one year participation of the TSYT, and the time is very pressing for them to finish the tasks assigned by the college. Besides, some young teachers only regard the TSYT as a task to finish, not an opportunity for development; they do not fully recognize the significance of the TSYT.

(2) Sluggishness of Participation, and Ineffectiveness of the Team of Tutors

At present, Jingjiang College has implemented the mode of "one-young-teacher-with-several-tutors", i.e., one young teacher is assigned to several corresponding tutors. In reality, only the primary tutor does have impact on the young teacher's development, the others shedding no or little influence at all. Those primary tutors are mainly (associate) professors, and most of them are in the administrative body of the college or of the department. They do not have sufficient time devoted to the TSYT because of their own heavy teaching and research load. As for the young teachers, some of them are sluggish in participating the TSYT. For example, some of them only attend the tutors' courses they are interested in; some are only present in their tutors' courses, but not actively participate, etc.

(3) Ambiguity of Assessment, and Shortage of Professional Evaluation

According to the Regulations on Assistant Teaching for Young Teachers at Jingjiang College, the assessment for the TSYT is composed of five aspects with a total score of 100 points, as are shown in Table 7. It can be seen from this table that these regulations have basically covered all the aspects of teaching capacities, but have no assessment items concerning teachers' professional knowledge and skills. For instance, these regulations do not mention capacities of lab demonstration for those who work at laboratories, and capacities of classification and categorization for those who serve at libraries, etc. Besides, some of the assessment are undertaken without the presence of professional teachers (i.e., only with administrative faculties). As a counter-measure for those limitations, it is advisable to add items of professional knowledge in the regulations and invite professional teachers to be members of the assessment team to have a more professional evaluation.

Table 7. Teaching Evaluations of Newly Recruited Young Teachers.

$\begin{array}{ll}\text { Teaching Beliefs (15\%) } & \begin{array}{l}\text { The teaching focuses on quality education, meets the needs of all students while respecting their peculiarities, and cultivates } \\ \text { students' innovative spirits, practical skills and humanities. } \\ \text { The teaching accords with the teaching objectives, meets students' current proficiencies, and the content is appropriate. The } \\ \text { teacher can adjust the teaching materials according to the nature of the course and the requirements of the syllabus, and cover } \\ \text { the key and important points explicitly. } \\ \text { Teaching Content }(30 \%)\end{array} \\ \text { Teaching Design (25\%) } & \begin{array}{l}\text { Theaching design is clear, and structurally as well as methodologically appropriate, and can foster students' learning } \\ \text { The teacher can organize and administer the teaching process appropriately with fluent, standard and concise language in a } \\ \text { natural posture. } \\ \text { The teaching achieves its objectives. The teaching atmosphere is excellent, and the whole teaching leaves a good general } \\ \text { Teaching Effects }(10 \%)\end{array}\end{array}$

\section{Methods and Strategies to Perfect the TSYT}

\subsection{Cultivating a Culture for Teacher Development and Enhancing the Publicity of TSYT}

Compared with regulations, cultural construction is more important [8]. It is impossible for the TSYT to have a positive effect within a school culture of isolation and separation [5]. Therefore, it is essential for the college to construct a school culture of teacher collaborations in which boundness and attraction could emerge as the result of interactive promotions in the TSYT. Such an interactive system could deepen young teachers' and their tutors' understanding of the tutorial system, and make them better understand their responsibilities, gains and obligations [9]. The young teachers in particular will be more active in participating the TSYT, get a clearer understanding of their obligations and responsibilities, master advanced teaching and research methods, integrate their own professional development with that of the college, and relate their short-term objectives with the long-term ones. Under such a system, young teachers could cultivate their own interest in teaching and develop rapidly in teaching and research, which finally improves the college's teaching quality and educational level.

Independent colleges in China have a relatively short history, and inevitably lack of profound historical and cultural basis. Though this might hinder the formation of a teacher development culture, it is much easier to form a peculiar and up-to-date teacher development culture without such existing cultural constraints. Thus, it is advisable for independent colleges to grasp this opportunity of forming new teacher cultures by fully exploiting the TSYT, creating a good atmosphere for teacher development, and forming a community of mutual development for all teachers.

\subsection{Perfecting Its Supportive System and Strengthening Monitoring of the Whole TSYT Process}

Fund guarantee is the basis for implementing the TSYT [10]. Jingjiang College allocates sufficient fund every year for tutors' subsidies in participating the tutorial system. If some tutor fails to complete the tasks, no subsidies will be given. If the teachers perform better or complete the tasks in TSYT effectively, they will be given priority in applying research grants, getting fund for compiling textbooks, and being 
elected as Excellent Faculty of the Year; otherwise, there will be some constraints. These measures are supposed to give material and spiritual stimulations, and make the college, young teachers and tutors pay more attention to the TSYT so as to facilitate the implementation and development of the tutorial system [11].

The monitoring of the whole TSYT process is essential for its quality control [12]. Thus, independent colleges should ensure the quality of the TSYT by trial teaching, evaluating and observing classes in situ, teaching check, and collecting class feedback. As a result, Jingjiang College has established the Leading Group of the TSYT and the Teaching Administrative Committee to guide and monitor the implementation of the TSYT. As concrete measures, the College should implement mid-term teaching checks, end-term teaching summaries, and monthly checks for young teachers' teaching. Besides, the Leading Group of the TSYT and the deans of each department should audit young teachers' classes in situ. These measures are supposed to bring professional, regular and standard measures for auditing, checking, and evaluating young teachers' actual teaching to ensure their best teaching attitudes and skills. The Teaching Administrative Committee will also share their teaching evaluations with the young teachers and their tutors and discuss these evaluations with them so as to not only reveal the problems, but also improve their teaching methods and effectiveness. At the end of each term, every tutor and young teacher will present the effect of the TSYT, and state their own achievements and limitations so that they could press and improve themselves [8].

\subsection{Optimizing the Content of Evaluation and Emphasizing Tutors' Formative Assessment}

As a counter measure to the same evaluation for all academic majors, the College should revise the content of evaluation with the help of leading committees from each major so as to better match the evaluation with the teaching practice of different majors. For examples, the ability to demonstrate experiments will be added to young teachers of medical examination, the ability to speak and write will be added to young teachers of foreign languages, etc. Under these measures, the evaluation is supposed to cover all the facets of teaching practice for different majors and is implemented by professionals.

Unobjective evaluations of the TSYT will hinder young teachers' development [13], and unfair ones will defeat their activeness in teaching. Thus, the College advocates formative evaluations for the TSYT by including the evaluations of the young teachers themselves, their tutors, the teaching administrative committee or the academic board, professors, peer teachers and students. To be specific, the young teachers participating the TSYT will first submit a self-evaluative report of their own development in the TSYT; then, evaluations will be given by students, peer teachers, professors of the same department, etc., and an other-evaluative report will be formed based on these evaluations; thirdly, the College's Teaching Administrative
Committee or the Academic Board will form a general evaluative report based on their own class-auditing, related checks, and the self and other evaluative reports formed in the previous two stages. The College will also implement related regulations and monitoring measures to ensure objective and fair evaluations of the whole evaluative process.

\subsection{Planning Thoroughly and Promoting the Sound Development of the TSYT}

Another key issue for implementing the TSYT is the compatibility between tutors and young teachers in terms of genders, personalities, majors, research interests, etc. After these issues setting down, the next major task is to plan thoroughly and implement precisely the TSYT. Therefore, young teachers should learn from their tutors in teaching, and record their feelings about their tutors' use of teaching resources, modes, methods, devices, languages, and non-linguistic skills. The tutors should provide related references for young teachers according to their major's peculiarities and the requirements of the syllabus, encourage young teachers to compile notes of the courses they offer so that young teachers could have a better understanding and command of the major's knowledge. Tutors should also organize various professional development activities (e.g., discussions, workshops, demonstration classes, etc.) for young teachers so that the latter would have more chances of applying their knowledge into practice and summarizing their own pains and gains in teaching. Also, tutors should observe young teacher's actual performance in teaching and provide timely feedback for their professional development.

\subsection{Utilizing Modern Information Technologies and Optimizing the Structure of Tutors and the Implementation of the TSYT}

The College should recruit as members of the tutor team more retired professors from Jiangsu University, and prominent teachers, teaching researchers as well as entrepreneurs inside and outside Jiangsu Province by exploiting modern information technologies. This will not only make up the insufficiency of tutors inside Jiangsu University, but also optimize the make-up of the tutors by adopting interactive network videoing for young teachers and their tutors. Alongside, some lectures and training programs can be stored in the internet for young teachers' later autonomous use, thus saving up human and material resources and improving the efficiency and effect of the TSYT. Jingjiang College has constructed and employed virtue network platforms to evaluate young teachers, and proved its feasibility in optimizing the structure of tutors and improving the implementation of the TSYT.

\section{Conclusion}

The TSYT has great impact on independent colleges' development. It is an effective means for young teachers' professional development and teaching skill education [14]. 
Jingjiang College has released the Regulations on Assistant Teaching for Young Teachers at Jingjiang College and these regulations has improved young teachers' educational levels, and produced positive effects on establishing a high-quality professional faculty. However, the implementation of the TSYT is a complex system, and there inevitably exist some problems or limitations [15]. For example, the young teachers' and their tutors' participation and devotion still need to be quantified, the TSYT lacks unitary content and standards, the reliability of the evaluations waits for further refinements, etc. All these problems await our solutions. To sum up, independent colleges should perfect and promote the TSYT by refining their evaluations and monitoring. Only in this way can they set up a good example for other independent colleges and form their own peculiarities.

\section{Acknowledgements}

This paper is funded by the project of Research on the Tutorial System for Young Teachers of Jiangsu University Jingjiang College (No. 13986jg2017B017).

\section{References}

[1] Luo, X. 2019. Young university teachers' professional dilemmas and reconstruction [J]. Jiangsu Higher Education, 7: 79-85.

[2] Huang, T. 2018. Analysis on the difficulties and countermeasures of the development of young teachers in colleges and universities [J]. Journal of North China University of Water Resources and Electronic Power, 6: 115-117.

[3] Tang, Y. 2020. Cultivating young teachers in universities: Challenges, tasks and strategies [J]. Modern Education Management, 1: 101-106.

[4] Degert, F., Dederer, V. \& Fukkink, R. 2020. The impact of in-service professional development on the quality of teacher child interactions in early education and care: A meta-analysis [J]. Educational Research Review, 29: 1-14.

[5] Lave, J. \& Wenger, E. 1991. Situated Learning: Legitimate Peripheral Participation [M]. Cambridge: Cambridge University Press.

[6] Gao, W. 2002. Teaching Modes [M]. Shanghai: Shanghai Educational Press.

[7] Yang, Q. 2008. Tutorship: An effective way for young teachers' development [J]. Journal of Ningbo University (Education Edition), 2: 88-90.

[8] Guo, Z. \& Wang, N. 2012. Reflections on evaluation of graduate tutors [J]. China Higher Education Research, 1: 56-58.

[9] Palonen, T. \& Erno, L. 2001. Exploring invisible scientific communities: Studying networking relations within an educational research community. A Finnish Case [J]. Higher Education, 42: 493-513.

[10] Zheng, D., Wu, G. \& Liu, Q. 2020. Taking the strengthening of young teacher training as a breakthrough to improve the overall teaching level of pharmaceutical college [J]. Guangdong Chemistry, 3: 242-243.

[11] Miao, Y. 2011. Tutorial system: A key way to the cultivation of young teachers in independent colleges [J]. Social Sciences Journal of Universities in Shanxi, 6: 105-108.

[12] Rudaleva, I., Kabasheva, I. \& Kovaleva, E. 2014. Factors satisfaction assessment of teachers professional activity [J]. Procedia: Social and Behavioral Sciences, 152: 1114-1120.

[13] Yao, J., Liu, J. \& Hu, H. 2017. The importance of tutor monitoring in cultivating young teachers $[\mathrm{J}]$. Course Education Research, 37: 199-200.

[14] Shen, Y. \& Li, Z. 2017. The cultivation and development system for young teachers at independent colleges [J]. Human Resources Development, 18: 97-98.

[15] Wang, F. 2017. On the Tutorial system for young teachers at local universities to improve their education competence $[\mathrm{J}]$. China Adult Education, 6: 124-127. 